\title{
Unusual mortality pattern among short term workers in the perfumery industry in Geneva
}

\author{
E GUBÉRAN, M USEL \\ From the Geneva Medical Inspectorate of Factories, $\mathrm{CH}-1207$ Geneva, Switzerland
}

ABSTRACT A cohort of 537 workers employed for less than one year between 1900 and 1964 in the Geneva perfumery industry was followed up from entry to the end of 1983. During the period of study, 251 workers died and $41(8 \%)$ were lost to follow up. The standardised mortality ratio (SMR) was significantly above 100 for all causes $(S M R=120)$, all cancers $(S M R=127)$, lung cancer $(S M R=186)$, and violent death $(S M R=179)$. The highest SMR from all causes was associated with the shortest period of employment (less than two months) and it decreased significantly with longer duration. Such mortality excesses had not been recorded among the 1168 workers of the same industry employed one year or more, previously studied in similar fashion. Interviews among a random sample of 52 workers employed for less than two months seem to indicate that the prevalence of smoking, exposure to asbestos, and occupational accidents in other hazardous industries were higher for these workers than for the reference population. Furthermore, unmarried men were overrepresented among the study cohort. These findings support previous observations indicating that short term workers share atypical features related to high mortality from various causes. It is suggested that mortality in this subgroup should be analysed separately in occupational studies.

We have previously described the mortality and the incidence of cancer among a cohort of 1168 workers of the Geneva perfumery industry first employed for at least one year in the period $1900-64$ and followed up to $1980 .{ }^{1}$ Overall mortality and overall incidence of cancer were similar to those of the Geneva male population and the cause specific analysis among the whole cohort showed that only mortality from tuberculosis was significantly raised.

In the present paper we analyse the mortality pattern of the workers employed for less than one year in the same industry.

\section{Population and methods}

The design of the present study was similar to that of the preceding study on workers with longer employment $^{1}$ except that the cut off date was the end of 1983 instead of 1980 . All workers employed for less than one year in the three factories of the Geneva perfumery industry since their establishment at the turn of the century until 31 December 1964 were included in the base population. Clerks, workers born before
1880 , and frontaliers (foreign workers commuting everyday into Swiss territory from neighbouring regions of France) were excluded as in the previous study (table 1). The 37 probationers were also excluded because their short term employment was assumed to have been planned before entry.

Data on the workers were extracted from the personnel registers which Swiss factory employers have had a legal duty to maintain since the end of the last

Table 1 Study cohort of short term workers by comparison with the cohort of workers employed one year or longer (as previously studied)

\begin{tabular}{llc}
\hline & $\begin{array}{l}\text { Employed } \\
<1 \text { year }\end{array}$ & $\begin{array}{c}\text { Employed } \\
\geqslant 1 \text { year }\end{array}$ \\
\hline Total No entering industry 1900-64 & 768 & 1471 \\
Excluded: & 47 & 186 \\
Clerks & 48 & 66 \\
Born <1880 & 68 & 51 \\
Frontaliers* & 37 & 0 \\
Probationers & $31(4 \%)$ & 1168 \\
Unidentified & 537 & 1006 \\
Study cohort & 467 & $2(0 \cdot 2 \%)$ \\
Swiss: & $6(1 \cdot 3 \%)$ & 162 \\
Lost to follow up & 70 & $26(16 \%)$ \\
Foreigners: & $35(50 \%)$ & \\
$\quad$ Lost to follow up & & \\
\hline
\end{tabular}

*Foreign workers commuting every day into Swiss territory from neighbouring regions of France. 
century. Unfortunately this regulation was abolished in the last revision of the law introduced in 1966. Because no register was missing and because many workers with a few days or only one day of employment were recorded, we believe that the study population was fairly complete, although we have no other source to check the personnel lists.

The workers were first identified and followed up in the records of the Population Office of Geneva. Eighteen Swiss and 13 foreign workers could not be identified, probably because most were never registered with that office or possibly because some old records were missing, and they were excluded. The remaining 537 workers were traced from entry to 31 December 1983 (245 alive) or to their death (251) or to the date at which their trace was lost (41 or $8 \%)$.

Inquiries about the 180 Swiss workers who left Geneva were made at their "commune of origin." According to a law first implemented in 1875 the communes have a duty to maintain a register on each family with data on birth, marriage, and death of all their "native citizens," and this is coordinated through a system enabling communication between all communes of the country. This system also includes Swiss citizens who emigrate provided that they register with a Swiss consulate, which, however, is not always the case. For this reason the 18 Swiss workers known to have emigrated were followed up through Swiss consulates and family members remaining in Switzerland. It was ascertained that six of these men were alive and six dead (three deaths had not been notified to the commune of origin). No information could be obtained on the remaining six who were considered lost to follow up.

Of 45 foreign workers who left Geneva only ten could be traced (five deaths) through the population office of other Swiss cities or through family members and 35 were lost to follow up. For the 79 Swiss and the three foreign workers traced alive and who were aged 64 and over at 31 December 1983, vital status was ascertained at the Swiss central pension scheme which keeps complete and accurate records on all old age pensions actually paid over the past five years in Switzerland or abroad.

Death certificates have been available since 1942 and the 24 deaths between 1900 and 1941 (of a total of 251) were included only in the general mortality analysis. The official death certificate codings were obtained for 212 of the 227 men who had died from 1942 onwards. Of the outstanding 15 cases, three certificates could not be found and the remaining 12 deaths occurred abroad; the cause of death remained unknown in seven of these. It was ascertained in five from information supplied by the hospital physician or the attending physician and in three from information obtained from the next of kin (two deaths from myocardial infarction and one from traffic accident

Incident cases of cancer were collected from 1 Jane uary 1970 (the date of inauguration of the Genevat Cancer Registry) to the end of 1983 among the 242 men who lived in the Geneva area during that period

Expected deaths and expected cases of cancer were calculated by the man-years method $^{2}$ using regionaf mortality and cancer incidence data, as described is detail elsewhere. ${ }^{13}$ The usual statistical analys based on the Poisson distribution was used to test the one sided significance of any excess of observed deaths or cases of cancer.

\section{STUDY SAMPLE}

A random sample was drawn from the subgroup of short term workers who stayed less than two month\$s It was actually postulated that these men, who has the highest excess mortality, were the most represeno tative for investigating atypical features related to short term employment. The 208 workers were stratified by year of birth and by nationality (Swiss and foreign) and a systematic sample of 52 men (1 in 4) was drawn. One man known to be alive had emp grated and 11 who had died had no relative who could be contacted. For these 12 the preceding mam on the list was sampled; the procedure had to be repeated on similar grounds for five of the cases a $\$ \infty$

A total of 69 workers was finally sampled ( 25 a five, 40 dead, four lost to follow up) and information 항하 collected on 52 . The non-response rate of $25 \%$ (1F) 69) was not unexpected considering the difficulties af tracing relatives of dead workers for a third of whor death had occured more than three decades ago.

Telephone interviews were made by one of us (EGwith the worker himself $(22 \mathrm{men})$ or with the next of kin (30 men). Details of lifelong smoking habits were collected and the successive occupations were listed with the available data on type of work and haz ardous exposure.

Smoking habits of the male population of the region were available from three studies of random samples, two drawn in the French speaking part of Switzerland in $1975^{4}$ and $1980^{5}$ and one drawn in the Geneva area in 1977-82. ${ }^{6}$ Smoking data from the three studies were combined and standardised to the age distribution of the sample of short term worket using three periods of birth (1880-99, 1900-19: 1920-39). Data on men born from 1940 onwards wes excluded because almost all short term workers weres born between 1880 and 1939. Smoking habits among manual workers, available from two of these stud ies, ${ }^{56}$ were similarly combined and standardised.

Two industrial hygienists with long experience the Geneva workplaces assessed exposure occupational lung carcinogens from the lifelong occupational histories of the 52 short term workes 
and of 78 men from a comparison group. The comparison group was constituted from the population controls selected among the above mention Geneva random sample for a case control study on laryngeal cancer (unpublished).Exposure was classified as very likely, possible, and unlikely.

\section{Results}

As may be seen in table 1 the short term workers were more difficult to trace than the workers employed for one year or longer in the same industry. Among the short term workers, $4 \%$ could not be identified and in addition $1.3 \%$ of the Swiss and $50 \%$ of the foreigner were lost to follow up, whereas the proportions were much lower among the workers employed for one year or longer.

\section{GENERAL AND CAUSE SPECIFIC MORTALITY}

The 537 short term workers contributed 16933 manyears of observation. For the whole study period (1900-83) 251 deaths are observed $v$ an expected 207.8 from regional death rates, giving a significantly higher SMR of $121 \quad(90 \%$ confidence interval: 109-134).

Table 2 shows the mortality from selected causes in 1942-83 (no death certificate being available before 1942), allowing for one year of latency as for the subsequent table. Mortality is significantly raised for all neoplasms, cancer of the lung, and violent death. A non-significant mortality excess is recorded for four other cancers (oesophagus, pancreas, bladder, and kidney), and for tuberculosis, chronic bronchitis, and emphysema, and circulatory disease. The latter excess is mainly accounted for by a non-significant increase in mortality from heart disease (observed deaths $(O)=53$, expected deaths $(E)=46 \cdot 2$ ) although the mortality from ischaemic heart disease, only available since 1969 , is not raised $(\mathrm{O}=12, \mathrm{E}=14 \cdot 6)$.

\section{CANCER INCIDENCE}

The analysis of cancer incidence covers only 1970-83 because there was no registry in Geneva before this. A total of 33 incident cancers is observed $v 30.5$ expected. No difference between observed and expected values reaches the level of statistical significance for the various cancer sites but the numbers are small in most comparisons. There is a nonsignificant excess in the incidence of lung cancer $(\mathrm{O}=10, \mathrm{E}=6.4, \mathrm{SMR}=156,90 \% \mathrm{CI}=85-265)$. Five additional cases of lung cancer, however, occurred in the cohort after the termination of the study (three in 1984 and two in 1985). These cases were fortuitously displayed because the search in the registry files was undertaken only in November 1985. Disregarding the fact that the collection of the cases by the registry was far from complete for 1985 , these five cases of lung cancer may be compared with the expected value which would be 0.9 if the number expected for $1983(0.43)$ is applied to the following two years. Taking this into account, the limited incidence data support the increased risk for lung cancer found in the mortality analysis.

Table 2 Mortality of short term workers from selected causes for 1942-83

\begin{tabular}{|c|c|c|c|c|}
\hline Cause (ICD code 8th rev) & Obs & $\operatorname{Exp}$ & $S M R$ & $90 \% \mathrm{CI}$ \\
\hline $\begin{array}{l}\text { All causes } \\
\text { All neoplasms (140-239): } \\
\text { Buccal cavity, pharynx (140-149) } \\
\text { Oesophagus (150) } \\
\text { Stomach (151) } \\
\text { Intestine, rectum (152-154) } \\
\text { Pancreas (157) } \\
\text { Larnyx }(161) \\
\text { Lung }(162,163 \cdot 0) \\
\text { Prostate }(185) \\
\text { Bladder }(188,223 \cdot 3) \\
\text { Kidney }(189 \cdot 0) \\
\text { Lymph/haemopoietic (200-209) } \\
\text { Others } \\
\text { Circulatory disease (390-458) } \\
\text { Violent death (E 800-999): } \\
\text { Motor vehicle accidents (E 810-823) } \\
\text { Other accidents (E 800-807, 825-949) } \\
\text { Suicide (E 950-959) } \\
\text { All other causes (0-136, 240-389, 460-796): } \\
\text { Tuberculosis (10-19) } \\
\text { Chronic bronchitis and emphysema (491-492) } \\
\text { Cirrhosis of liver (571) } \\
\text { Unknown }\end{array}$ & $\begin{array}{r}227 \\
69 \\
3 \\
6 \\
5 \\
5 \\
5 \\
1 \\
24 \\
3 \\
5 \\
2 \\
3 \\
7 \\
76 \\
28 \\
7 \\
12 \\
9 \\
47 \\
8 \\
5 \\
4 \\
4\end{array}$ & $\begin{array}{r}189 \cdot 9 \\
54 \cdot 4 \\
2 \cdot 8 \\
2 \cdot 9 \\
5 \cdot 0 \\
6 \cdot 2 \\
2 \cdot 1 \\
1 \cdot 5 \\
12 \cdot 9 \\
5 \cdot 0 \\
2 \cdot 5 \\
1 \cdot 2 \\
3 \cdot 2 \\
9 \cdot 1 \\
66 \cdot 6 \\
15 \cdot 6 \\
3 \cdot 4 \\
5 \cdot 9 \\
5 \cdot 8 \\
53 \cdot 3 \\
4 \cdot 4 \\
3 \cdot 4 \\
6 \cdot 5\end{array}$ & $\begin{array}{c}120^{* *} \\
127^{*} \\
107 \\
207 \\
100 \\
81 \\
238 \\
67 \\
186^{* *} \\
60 \\
200 \\
167 \\
94 \\
77 \\
114 \\
179 * * \\
206 \\
203 * \\
155 \\
88 \\
182 \\
147 \\
62\end{array}$ & $\begin{array}{r}107-133 \\
103-155 \\
29-277 \\
90-408 \\
39-210 \\
32-170 \\
94-501 \\
3-316 \\
128-262 \\
16-155 \\
79-421 \\
30-525 \\
26-242 \\
36-144 \\
93-138 \\
128-246 \\
97-387 \\
117-330 \\
81-271 \\
68-112 \\
90-328 \\
58-309 \\
21-141\end{array}$ \\
\hline
\end{tabular}

$\mathbf{C I}=$ Confidence interval

${ }^{*} \mathrm{p}<0.05,{ }^{* *} \mathrm{p}<0.01$ 


\section{MORTALITY AMONG SUBGROUPS}

As shown in table 3 there is a downward trend of mortality with longer employment, which is significant at the $5 \%$ level ( $\chi^{2}$-test). The SMR is highest $(140, \mathrm{p}<0.01)$ for those who stayed less than two months and there is no mortality excess $(\mathrm{SMR}=92)$ for those who remained employed at least half a year. Among the former there is a great increase in mortality from violent death $(O=16, E=6 \cdot 1$, SMR $=262,90 \% \mathrm{CI}=165-398)$, which was particularly high for the years one to 14 after entry due to three deaths from accident and four from suicide $(\mathrm{O}=7, \mathrm{E}=1 \cdot 2, \mathrm{SMR}=583,90 \% \mathrm{CI}=274-1096)$.

A trend, although not significant, is also observed in the analysis by age at death (table 3), with SMRs of 146 for the youngest age group (15 to 49) and of 111 for the oldest. Among the youngest age group much of the excess may be ascribed to the high mortality from neoplasms $(\mathrm{O}=8, \mathrm{E}=4.4)$ and from violent death $(\mathrm{O}=15, \mathrm{E}=6 \cdot 1)$.

On the other hand, there is no trend of mortality by year of entry (table 3 ). This contrasts with the finding among the workers who stayed one year or more whose SMR from all causes was significantly raised for those born before 1900 and first employed before 1930 , whereas no excess mortality was observed in the other subgroups. ${ }^{1}$

According to registered occupation at entry, the 537 short term workers have been distributed in three categories: chemists $(n=18$ or $3 \%)$, maintenance $(n=74,14 \%)$, and production $(n=445,83 \%)$. The latter category includes a few workers in miscellaneous occupations such as dispatching, handling, or driving. Production workers $(\mathrm{O}=213, \mathrm{E}=175 \cdot 2$,
$\mathrm{SMR}=122,90 \% \mathrm{CI}=108-136)$ and maintenanc workers $(\mathrm{O}=24, \quad \mathrm{E}=19.8, \quad \mathrm{SMR}=121, \quad 90 \%$ $\mathrm{CI}=84-170$ ) share a similar excess mortality. As: with the chemists who stayed one year or more, ${ }^{1}$ the "short term chemists" had a lower mortality tha? other categories $(O=14, E=12 \cdot 8, \quad S M R=10$ S. $90 \% \mathrm{CI}=66-171$ ), although the small number of deaths precludes any interpretation.

\section{LUNG CANCER}

The significant excess mortality from lung cance? (table 2) suggests a high rate of smoking among the्ठ

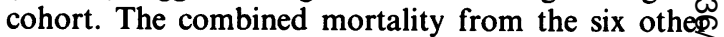
smoking related cancers ${ }^{7}$ (buccal cavity and pharynx oesophagus, pancreas, larynx, bladder, and kidney尹 is also significantly increased $(O=22, E=13.0+5$ SMR $=169,90 \% \mathrm{CI}=115-242)$ whereas the come bined mortality from all other cancers is not $(\mathrm{O}=23 \mathrm{c}$ $\mathrm{E}=28 \cdot 5, \mathrm{SMR}=81,90 \% \mathrm{CI}=55-114$ )

As may be seen in table 4 the short term worker\& seem to smoke significantly more than both men in general from the region and manual workers from the same region. In addition, three of the six short tern workers classified as never smokers might have bee ex-smokers because the smoking history obtaine $\bar{\Phi}$ from the relative (a niece, a second wife, and a brother in law) did not cover young adult life.

Contrary to the study sample, however, the the random samples from the general population wèे assembled cross sectionally and did not include nere who died prematurely. Smokers were probably over represented among the latter. This "survivor bias" ిㅛ cannot be overlooked but its effect might be limite considering the smoking habits of the 22 short term

Table 3 Mortality 1900-83 from all causes in various subgroups of short term workers

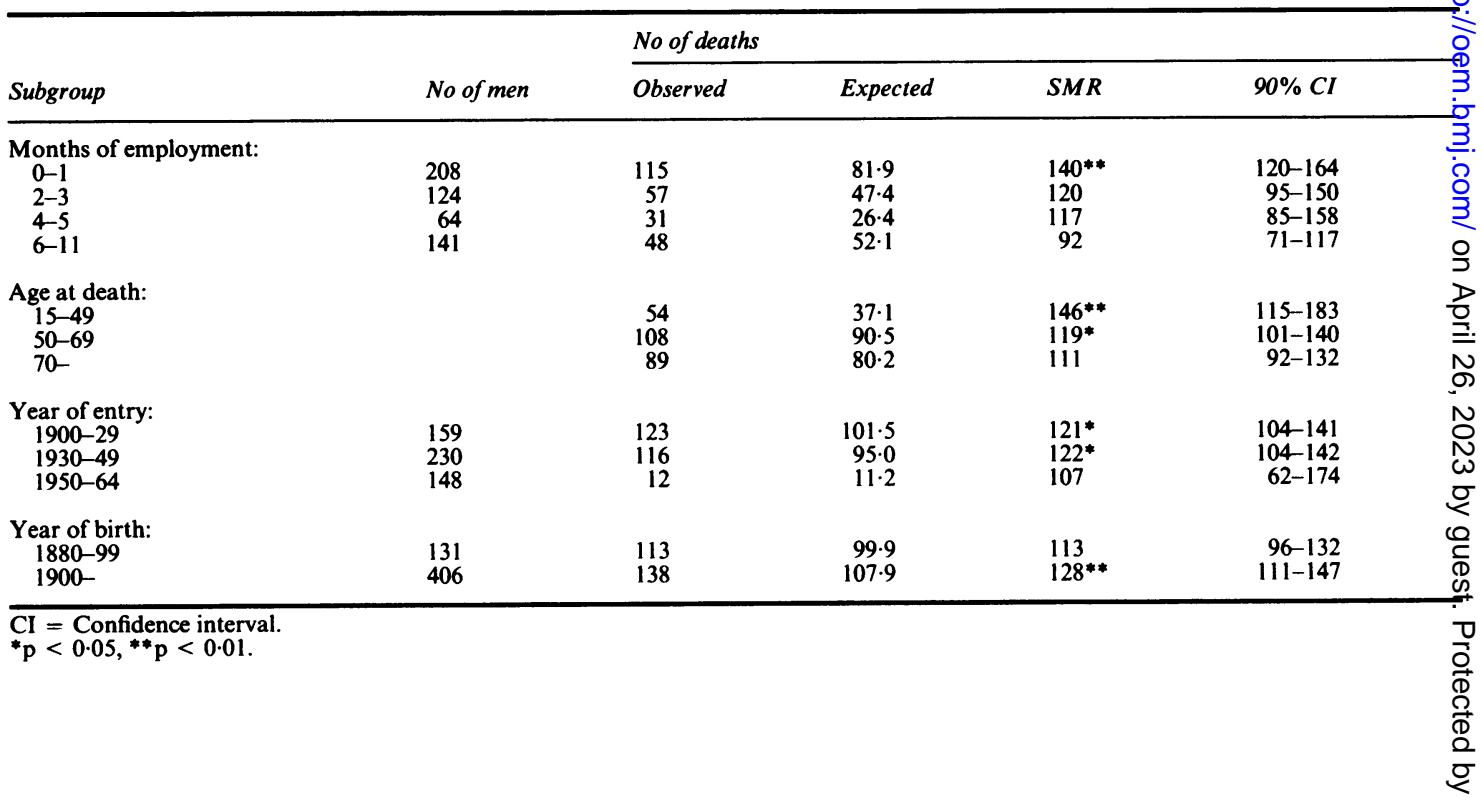


Table 4 Percentages by smoking category among the sample of short term workers and among all men and manual workers from the region (combined results of three random samples: see methods)

\begin{tabular}{llll}
\hline & & General population \\
\cline { 3 - 4 } Smoking category & Short term workers $\left(n=49^{*}\right)$ & All men $(n=815)$ & Manual workers $(n=215)$ \\
\hline Never smokers $(\%)$ & $12 \cdot 2$ & $28 \cdot 7$ & $22 \cdot 0$ \\
Ex-smokers (\%) & $20 \cdot 4$ & $42 \cdot 9$ & $45 \cdot 8$ \\
Cigar, pipe smokers (\%) & $10 \cdot 2$ & $4 \cdot 3$ & $4 \cdot 3$ \\
Cigarette smokers (\%) & $57 \cdot 1$ & $24 \cdot 1$ & $28 \cdot 0$ \\
\hline
\end{tabular}

* Smoking habits not ascertained in three of the 52 workers.

Significant difference $\left(\chi^{2}\right.$ test) between short term workers and either all men $(p<0.001)$ or manual workers only $(p<0.001)$.

workers who were personally interviewed $(9 \cdot 1 \%$ never smokers, $36 \cdot 4 \%$ ex-smokers, $4 \cdot 5 \%$ cigar or pipe smokers, and $50.0 \%$ cigarette smokers), which are also significantly higher than those of the population $(\mathrm{p}<0.05)$.

To evaluate the confounding effect of the smoking habits among the short term workers on their lung cancer mortality, the procedure described by Axelson ${ }^{9}$ was applied to the data of table 4 using relative risks obtained in the United States veterans study ${ }^{10}(1.0$ for never smokers, 4.0 for ex-smokers, 1.9 for pipe or cigar smokers, and 11.3 for cigarette smokers). Under such assumptions the SMR from lung cancer among the study cohort would be 158 due to smoking alone.

An attempt was also made to assess the occupational exposure to lung carcinogens from the lifelong occupational histories of the sample of 52 short term workers and of a comparison group of 78 men (see Methods). Results indicate that $28.8 \%$ of the short term workers and $14.1 \%$ of the men from the comparison group were likely to have been exposed to asbestos for more than five years-for example, in boiler making, carpentry, electrical installation, gas work, or automobile repair. The proportions of men possibly exposed to asbestos were respectively $13.5 \%$ and $7.7 \%$, and of men unlikely to have had exposure, $57 \cdot 7 \%$ and $78 \cdot 2 \%$.

Exposure to other occupational lung carcinogens, mainly polycyclic hydrocarbons, nickel, chromium, and arsenic compounds was less frequent and more difficult to assess, and was therefore disregarded.

Taking into account the combined effect of asbestos and tobacco smoke in causing lung cancer ${ }^{11}$ the likely higher prevalence of asbestos exposure among the study cohort than the reference population might account for a limited part of the excess risk for lung cancer among the short term workers.

\section{VIOLENT DEATH}

Excess mortality from accident and suicide related to alcohol abuse has been reported in many studies-for example, Thorarinsson ${ }^{12}$ and Nashold and Naor ${ }^{13}$ and this factor might be related to the significant increase in mortality from violent death among the study cohort. There is no excess mortality from hepatic cirrhosis $(O=4, E=6 \cdot 5)$, only one death from alcoholism (ICD-8: 303), and none from alcoholic psychosis (291) or alcohol poisoning (860). On the other hand, one of the four above mentioned diagnoses appears as an associated cause of death on 10 of a total of 212 available death certificates $(4 \cdot 7 \%)$.

These results are to be compared with those obtained for four other cohorts that we have studied in Geneva and which were constituted by the perfumery workers who stayed one year or longer, ${ }^{1}$ by 703 male hairdressers, ${ }^{3}$ by 1917 painters, and by 1948 electricians (last two studies not yet published). The observed $v$ expected deaths from hepatic cirrhosis were respectively $14 / 11 \cdot 3,11 / 10 \cdot 1,14 / 8 \cdot 8$, and $4 / 5 \cdot 9$. The proportions of the death certificates which mention, as associated cause of death, cirrhosis or any form of alcoholism (ICD-8: 291, 303, 860) were respectively $5.4 \% \quad(n=17), 3.0 \% \quad(n=9), 5.6 \%$ $(n=14)$, and $3.8 \%(n=5)$. Thus the limited evidence obtained from the mortality data does not support the hypothesis of higher alcohol abuse among the short term workers.

Further scrutiny of the death certificates indicates that four of the 19 accidental deaths in the study cohort were of occupational origin compared with only two of 24 among the perfumery workers employed for more than one year, although two additional deaths were due to chronic benzene poisoning. ${ }^{1}$ Analysis of the 52 occupational histories of the short term workers shows that $11(21 \%)$ spent most of their active life in the construction industry, road maintenance, and forestry, which are among the occupations with the highest mortality rates from accidents in Switzerland. Thus some part of the excess deaths from accidents among the short term workers might be related to higher than average exposure to occupational accidents in other hazardous industries.

Previous studies of mortality by social class and by marital status ${ }^{14-16}$ have shown a steep mortality gradient for violent death from the more skilled to the 
less skilled occupations. A sharp mortality differential between married and unmarried men has also been shown. Tables 5 and 6 show that both unskilled and unmarried workers were overrepresented in the study cohort. The limited differences between the short term workers and the reference population, however, could account for only a small part of the excess mortality from violent deaths.

\section{LIFELONG CAREER OF SHORT TERM WOREERS}

According to the personnel records of the three perfumery factories, $38(73 \%)$ of the 52 workers sampled were engaged in unskilled occupations, 13 in skilled occupations, and one was a chemist. Scrutiny of occupational histories indicates that 16 workers (31\%) remained unstable, all but one in unskilled occupations, and may be considered as "lifelong short term workers," whereas 14 workers $(27 \%)$ had fairly stable careers with a few changes within the same occupation. The remaining 22 workers (42\%) may be classified as "intermediate" so far as occupational stability is concerned. As may be inferred from table 5 , most of the 52 men moved up the socioeconomic categories after their short term employment in the perfumery industry when $80 \%$ of them were aged below 30.

Various explanations concerning the shortness of their period of employment were given by the workers who were personally interviewed. Several men evoked dislike of the work, rashes, or unbearable smells from the aromatic chemicals; one man claimed that he liked the job but the smell of violets made him feel faint. Other workers had already planned a short stay while looking for another occupation.

\section{Discaion}

In a cohort study of beryllium workers published in 1970 Mancuso found higher death rates among men exposed for up to 14 months than among those exposed for 15 months or more. ${ }^{17}$ The ratio of age

Table 5 Percentages by socioeconomic category among the sample of short term workers (according to the main bifelong occupation) and among all active men from Geneva (mean results of the 1941, 1950, and 1960 census)

\begin{tabular}{|c|c|c|}
\hline Occerpation & $\begin{array}{l}\text { Short term } \\
\text { morters } \\
(n=52)\end{array}$ & $\begin{array}{l}\text { Geneva male } \\
\text { population } \\
(n=70265)\end{array}$ \\
\hline \multirow{2}{*}{ 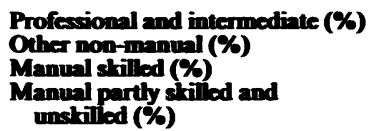 } & $\begin{array}{l}13-5 \\
19-2 \\
28-8\end{array}$ & $\begin{array}{l}24-3 \\
24-0 \\
26-5\end{array}$ \\
\hline & $38-5$ & $25-1$ \\
\hline
\end{tabular}

There is a significant trend $(p<001)$ for short term workers to be more probably employed in manual and und sillod occupations as compared with the Geneva male population ( $x^{2}$ for trend).
Table 6 Percentages by marital status among the short terns workers resident in Geneva at 1 January 1970 (mean age 50-6) and among the morkers employed one year or more resident in Geneva at 1 Jamury 1974 (mean age 506 years) $\overrightarrow{\overrightarrow{\bar{N}}}$

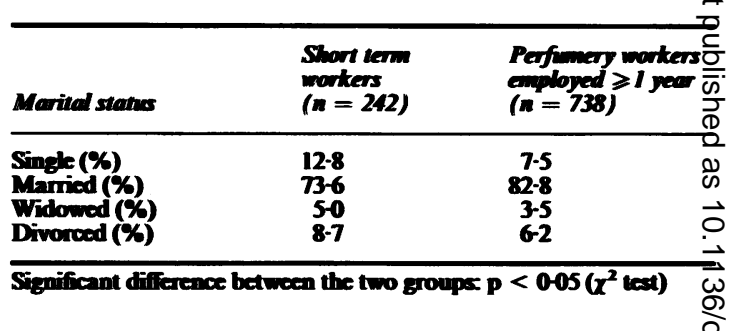

adjusted death rates was 1-11 for overall mortality (based on 500 deaths), 1-27 for all neoplasms, 3-01 fot lung cancer, 2.03 for diseases of the respiratory sysio tem, and 1-24 for accidents and poisoning. In recerff years additional evidence of odd mortality pattern's' for short term workers has been reported in chemical workers in Texas (significant increase in mortality from all causes and from circulatory disease), ${ }^{18}$ if Australian fire fighters (all causes, trafic accidents), $\stackrel{10}{\mathbb{1}}$ in asbestos workers in Connecticut (all causes, af neoplasms, respiratory cancers and heart disease), ${ }^{20}$ and in nuclear workers in Hanford (all causes, infectious diseases, ill defined conditions, and vioberffe death). ${ }^{21}$ By contrast, no significant excess in noportality related to short term employment was found studies of United States dye workers, ${ }^{22}$ asbesto workers in South Carolina and Pennsylvania, ${ }^{23} 2 \frac{1}{0}$ uranium workers in Tennessee, ${ }^{25}$ pesticide workers if Baltimore, ${ }^{26}$ chrysotile miners and aluminium worl 8 ers in Quebec, ${ }^{27} 28$ and Swedish railroad maintenance shopworkers. ${ }^{29}$ No convincing explanation of the unexpected mortality excesses has been offered by theauthors of the "positive" studies.

The 537 short term workers who entered the Geneva perfumery industry between 1900 and 1969 have experienced a significantly higher mortality from all causes, all cancers, lung cancer, and violent deatho whereas no significant excess mortality for thesie causes has been found among the workers of the sam industry employed for one year or more.' It seems that most of the increase in cancer mortality may be ascribed to smoking, considering the high smokin habits recorded among the study sample and the. finding that the smoking related cancers accountefy for the whole excess in cancer mortality. There is alsip limited evidence that occupational exposure to asbes? tos in other hazardous industries, combined with the effect of smoking, might have contributed to the high mortality from lung cancer.

By contrast it is difficult to suggest what facto might be accountable for the excess mortality from accidents and suicide, which was particularly preㅇํㅇ 
dominant among the workers who stayed less than two months. As we have seen, the prevalence of alcoholism is unlikely to be increased among the study cohort and only a small part of the mortality excess for violent death might be attributed to the association of short term employment with unskilled occupation and with unmarried status.

From our results and from those of about half the quoted studies there is evidence of an odd mortality pattern among very short term workers. These findings have important implications for studies of occupational cohorts and suggest that this subgroup should be studied separately and excluded from any analysis of the relation between the duration of exposure to an occupational hazard and the subsequent mortality or disease incidence.

We are indebted to Mr P M Sweetnam from the MRC Epidemiology Unit, Cardiff, for his invaluable advice and support, Mr P Desbaumes and Mr A Jaques for

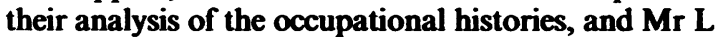
Raymond for providing the data of the Geneva Cancer Registry. We thank Dr F Paccaud and Dr A Morabia for their kind criticisms of the manuscript and Mrs N Cruz, Mrs U Oberkampf, Mr P Brulhart, Mr R Mermoud, Mr H Steffen, and Mr V Wietlisbach for their help. We also thank Givaudan and Firmenich companies for their cooperation and interest.

\section{References}

1 Gubéran E, Raymond L. Mortality and cancer incidence in the perfumery and flavour industry of Geneva. Br $J$ lnd Med 1985; $42: 240-5$.

2 Hill ID. Computing man years at risk. Br J Prev Med 1972;26:132-4.

3 Guberan E, Raymond I . Sweetnam PM. Increased risł for male bladder cancer among a cohort of male and female hairdressers from Geneva. Int J Epidemiol 1985;14:549-54.

4 Abelin T, Wūthrich P. Reprāsentativerhebung über die Rauchgewohnheiten in der deutsch-, französisch- und romanischsprachigen Schweiz 1975. Soz Pranentivmed 1976;21:17-23.

5 Autorengruppe SOMIPOPS (manuscript: F Gutzwiller). Die Haushaltbefragung: Methoden zur Definition und Erfassung von Gesundheits- und Versorgungsindikatoren. Soz Praventivmed 1981;26:21-5.

6 Esteve J, Tuyns AJ, Raymond L, Vineis P. Tobacoo and the risk of cancer. Importance of kinds of tobacco.In: O'Neill IK, Von Borstel RC, Miller CT, Long J, Bartsch H, eds. N-Nitraso compounds: occurrence, biological effects ind relevance to human cancer. Lyon: International Agency for Research on Cancer, 1984:867-76. (IARC sci publ No 57.)
7 Doll R, Peto R. The couses of cancer. New York: Oxford University Press, 1981:1220-4, $1238-45$.

8 Kleinbaum DG, Morgenstern H, Kupper LL. Selection bias in epidemiologic studies. Am J Epidemiol 1981;113:452-63.

9 Axelson 0 . Aspects of confounding and effect modification in the assessment of occupational cancer risk. J Toxicol Envirom Health 1980;6:1127-31.

10 Rogot E, Murray JL. Smoking and causes of death among US veterans: 16 years of observation. Public Health Rep 1980;55:213-22.

11 Hammond EC, Selikof I, Scidman H. Asbestos exposure, cigarette smoking and death rates. Amn NY Acad Sci 1979;33:473-90.

12 Thorarinsson AA. Mortality among men alcoholies in Iceland, 1951-74. J Stud Alcohol 1979;-10:-704-18.

13 Nashold RD, Naor EM. Alcohol-rehted deaths in Wisconsin: the impact of alcohol on mortahity. Am J Public Healh 1981;71:1237-41.

14 Registrar General. Statistical review of England and Wales for the year 1967. Part III. London: HMSO, 1971:136-40.

15 Fox AJ, Goldblatt PO. Socio-denographic mortality differentials: longitudinal study 1971-5. London: HMSO, 1982:30, 38, 46. (Series LS No 1.)

16 Pearce NE, Davis PB, Smith AH, Foeter FH. Social chass, ethnic group, and male mortality in New Zealand, 1974-8. J Eppdemiol Commenity Health 1985;3,9-14.

17 Mancuso TF. Relation of duration of employment and prior respiratory illness to respiratory cancer among beryllium workers. Environ Res 1970;3:251-75.

18 Bond GG, Reeve GR, Ot MG, Waxweiler RJ. Mortality among a sample of chemical company employees. Am J lnd Med 1985;7:109-21.

19 Eliopulos E, Armstrong BK, Spictett JT, Heyworth F. Mortality of fire fighters in Western Australia. Br $J$ Ind Med 1984;41:183-7.

20 McDonald AD, Fry JS, Woolley AJ, McDonald JC. Dust exposure and mortality in an American chrysotile asbestos friction products plant. $B$ H Ind Med 1984;41:151-7.

21 Gilbert ES. Some confounding factors in the study of mortality and occupational exposures. Am J Epidemiol 1982;116:177-88.

22 Ot MG, Langner RR. A mortality survey of men engaged in the manufacture of organic dyes. J Occap Med 1983;25:763-8.

23 McDonald AD, Fry JS, Woolley AJ, McDonald J. Dust exposure and mortality in an American chrysotile textile plant. Br $J$ Ind Med 1983;40:361-7.

24 McDonald AD, Fry JS, Woolley AJ, McDonald JC. Dust exposure and mortality in an American factory using chrysotile, amosite, and crocidolite in mainly textile manufacture. Br J Ind Med 1982:39:368-74.

25 Polednak AP, Frome EL. Mortality among men employed between 1943 and 1947 at a uramium-processing plant. J Occup Med 1981;23:169-78.

26 Mabuchi K, Lilienfedd AM, Saell.LM. Cancer and occupational exposure to arsenic: a study of pesticide workers. Prer Med 1980,9.51-77.

27 McDonald JC, Liddell FD, Gibbs GW, Eyssen GE, McDonald AD. Dust exposure and mortality in chrysotile mining. 1910-75. Br J Ind Med 1980;37:11-24.

28 Gibbs GW. Mortality of aluminium reduction plant workers, 1950 through 1977. J Occup Med 1985:27:761-70.

29 Ohlson CG, Klaesson B, Hogstedt C. Mortality among asbestosexposed workers in a railroed workshop. Scand J Work Environ Health 1984;10:283-91. 